\title{
Sketching the Polyphonic Design Space of Theme Parks
}

\begin{abstract}
Abigail Durrant, Northumbria University, abigail.durrant@northumbria.ac.uk Michael Golembewski, Microsoft Research, mike.golembewski@gmail.com David Kirk, Northumbria University, david.kirk@northumbria.ac.uk
\end{abstract}

\section{INTRODUCTION}

Drawing is a fundamental human practice of making sense of the world and communicating ideas. It gives form to acts of imagination and free thought, enabling not only collaboration but also co-creation (Petherbridge, 2010). As such, drawing can be fundamental to design practice. We can think about sketching as a particular type of drawing activity that helps practitioners refine, explore, and understand complex systems and concepts (Allen, 1999). Design sketching is well explored in relation to cognition and expression through action (e.g. Arnheim, 1995; Fish and Scrivener 1990; Gedenryd, 1998; Schon and Wiggins, 1992), and has been open to new interpretation and relevance as computer-related technologies have developed and proliferated (e.g. Gross and Yi-Luen Do, 2004; Tovey, 1989; Winograd 1996). In the field of Human Computer Interaction (HCI), design sketching practices have been transformed by, amongst other things, new digital tools for making and collaborating (e.g. Scrivener et al 1994). Creative design techniques have matured for prototyping through sketching as a generative endeavour, in particular to attend to user experience (e.g. Buxton 2007; Carroll, 2000; Fallman, 2003, Moggridge, 2007), or to envision possible worlds (e.g. Bleecker, 2009; Blythe, 2014; Kirby, 2009; Morrison et al, 2013), or in visual argumentation and dissemination (e.g. Gaver 2011; Gaver 2012; Gaver and Bowers 2012).

In this chapter, we consider sketching in an HCI research context that seems apt for inclusion in a book about Funology: the theme park. Specifically, the research project investigated technology and service design opportunities in a UK theme park setting, grounded in experiences of visiting. As members of the project team with backgrounds in art, design, psychology and ergonomics, we present a collective account of ideation and prototyping activities that engaged our project partners and stakeholders. We consider design sketching as a dialogical process (Wright and McCarthy 2005), and describe how we used the medium of sequential art for pictorial expression (Eisner, 2008; McCloud 2001) in ways that enabled the complexity of both our setting and our design space to be identified and worked with. We had a precedent for working with this medium to pursue HCI research (Rowland 2010) that informed our approach. Central to our account is a proposition that our sketching process afforded us a deep level of collaborative, empathetic, and speculative engagement with our subject, which we valued as constructive and enjoyable.

In broad terms, the project set out to explore how novel pervasive computing configurations in the theme park could enhance visitor experience. The research was part of a UK-funded academic programme (http://horizon.ac.uk) exploring opportunities for product and service innovation based on new empirical understandings of personal data interactions in people's everyday lives. The project team was interdisciplinary, with other members contributing expertise in computer science and business studies. The theme park was one of a number of settings where we conducted our research, and provided a particular context of cultural engagement to investigate. Our commercial partner operated in the entertainment sector and owned the theme park that became our particular setting. Our approach was experience-centred (McCarthy and Wright 2004; McCarthy and Wright 2015), and involved observational fieldwork and interviews alongside design practice. 
Responding to empirical insights and using the medium of sequential art, we - the three authors - developed a picture book (Nikolajeva and Scott, 2000) that captured a collection of conceptual designs, depicted in the speculative context of characterdriven scenarios (Blythe and Wright, 2006; Wright and McCarthy, 2005). Our method was informed by the literary theory of Mikhail Bakhtin, after Wright and McCarthy (2005), and Bakhtin's concept of Dialogism (Bakhtin, 1981). Specifically, we drew on his conceptualisation of polyphony, a literary device for supporting the expression of multiple authorial voices. The picture book scenarios became a valuable resource, not just for expressing diverse ideas and perspectives within the design space of our interests, but also for fostering dialogue between the research team members, and with our partnering stakeholders, as we will go on to describe.

The project provides an example of a design-based, interdisciplinary inquiry in which the practice of sketching and storyboarding was instrumental to the generation of ideas, collective understanding, and for experiential engagement with the empirical materials. The account of our practice in this chapter has three narrative strands that deliver three interlinked sets of insights. One strand explores the aesthetic experience of sketching as a form of collaborative design inquiry, leveraging multiple versions of hand-drawn and computer-aided sketches in the development of ideas. A second strand reflects on the use of sequential art and fictional scenarios to create and explore a polyphonic design space. Multiple perspectives on theme park visiting are combined to depict a speculative, character-driven storyworld (diegesis) that is populated with new design ideas. The third narrative strand describes how the conceptual design inquiry was pursued in conjunction with empirical fieldwork, interviews, and evaluations of prototype technology; the activities were mutually informing. The picture book also enabled a broader conversation with our stakeholders and partners, enabling considerations for strategic innovation to be elucidated and 'entertained'.

\section{THE THEME PARK}

The theme park presents a distinct commercial setting for HCI research. It is a place with a specific cultural identity, geared around fun, thrill, and memorable experiences, and is routinely experienced across the world (Adams 1991; Cross and Walton 2005; Jones and Wills 2005). It represents and realises visions of fantastical and future worlds, inviting its visitors to escape from their ordinary lives. It has also often represented a space for utopian speculation - the visions of Disney's EPCOT Center being a notable example (Gennawey, 2011), a place where both new interactive technologies and proposals for new ways of living are explored. In this regard, the theme park is often seen as a space in which the play of possibilities of new design ideas and technology interactions can come to fruition - a technological proving ground. Yet despite its 'fantastical' aspects, the park is still a world of mundane practicalities and orderly interactions, the combination of which gives rise to a host of intriguing considerations for HCI researchers (Durrant et al 2012).

Extant studies of leisure settings and practices of cultural visiting are extensive in the humanities and social sciences (e.g. Cross and Walton 2005, Moore 1980), especially for tourism (Harrison 2001). HCI researchers have explored current (Brown and Juhlin 2015) and future (Rennick-Egglestone et al 2016) uses of digital technology within these settings. Such studies often focus on how technologies shape practices of visiting. This is particularly notable in Bell's (2002) articulation of museum spaces as 'cultural ecologies', curated to promote certain kinds of message and to scaffold certain kinds of experience that will shape visiting as part of an inherently sociotechnical activity extending beyond the museum space itself. Another conceptual framework that has gained purchase in HCI for studying cultural engagement focuses on how such 'trajectories of experience' (Benford and Giannachi 2011) may be supported by interaction design.

Many of the HCI studies of visiting practices focus on the roles and use of mobile 
technologies (Brown and Chalmers 2003) and mobile 'photoware' (Sarvas and Frohlich 2011), designed to support engagement with cultural events or entertainment (e.g. Salovaara et al 2006, Jacucci et al 2007a, 2007b), or the capture of these events for posterity (Durrant et al 2011). The now-ubiquitous availability of cameras on smartphones opens up new opportunities for creating photo-based souvenirs (ibid).

The potential role of data as a new form of record within the production and consumption of 'souvenirs' has been a recurrent interest within studies of the 'digital economy' in the UK (Nissen et al, 2014) and within literature on personal informatics (Elsden et al, 2017). The commodification of data has been seen in recent times as a new mass-market ripe for exploitation (Beer and Burrows 2013). This is interesting to consider in the setting of the theme park, as a commercial enterprise that exploits the provision of added value services through its dedicated infrastructure. It is worth noting that our research reported herein was conducted between 2009 and 2011 at a time when there was strategic interest in location based services. Our commercial partner was Merlin Entertainments, and Alton Towers Resort, a theme park managed by Merlin, was the setting for our case. At the time of study, Alton Towers welcomed around 2.8 million visitors per year, forming a resort site with flagship roller coasters set amongst gardens and other attractions, organised around themed zones. At the time of study there was minimal networked infrastructure in place, and the business was keen to speculate on how its souvenir systems could be digitally enhanced.

\section{CONSUMING EXPERIENCE}

Our research at Alton Towers set out to explore how emerging pervasive computing could enhance visitor experiences in the theme park setting. We focused on aspects of experiential engagement with the theme park and its consumables. Our observational fieldwork (conducted by Durrant and Kirk) revealed how this park is designed to promote and tightly choreograph 'out-of-the-ordinary' experiences; such experiences were scaffolded and steered by park furniture, landscaping and signage, including maps, queue lanes to rides, and the careful placement of cafes and stalls for consuming refreshments and post-ride souvenirs. Also, individuals within visiting groups used their smartphones and other personal devices to capture and consume their own entertainment and expressions of their visit. This led to the analysis of individual trajectories of experience through the park (Benford and Giannachi 2011).

A striking feature of these trajectories was how a 'day in the park', for any given visitor, comprised of a range of experiences that could be positive and negative in emotional and physiological charge. A visit could encompass moments of heightened sensory awareness like thrill, as well as less memorable or mundane times, or even events that should be forgotten. Diverse affective experiences were expressed within visiting groups, too, sometimes about a shared engagement in a ride or another park activity. Such trajectories could be interpreted in narrative terms, and we found value in using Bakhtinian concepts to guide our analysis of participants' accounts. Bakhtin argued that literary devices can be engaged with as a resource for exploring and understanding human experience; his insight has been identified and operationalised for HCI design by Wright and McCarthy (2005), amongst others. In particular his notion of polyphony (1984), taken from the genre of the polyphonic novel, helped us to attend to the 'multivoicedness' (or polyvocality) evidenced in the data. This analytic lens foregrounded the multiplicity of experiences voiced within an individual's visit, and visitors' 'reading' and meaning-making around souvenirs, captured in post-hoc interviews. Also foregrounded in the data was the continuing and pluralistic nature of sense making on theme park visiting in groups, and on souvenir consumption.

We were keen to understand how emerging pervasive technologies could become integrated with the aesthetic experiences of visiting. In particular, we were keen to explore how services could be designed to accommodate differing orientations towards 'being entertained' and more actively 'pursuing leisure' (Durrant et al 2012). We saw an opportunity to develop new kinds of service provision within the park that 
would support the co-production and consumption of theme park experience by both the park and its visitors. Such service provision could utilise the park's systems as well as the visitors' own personal devices in the co-creation of souvenirs.

In the following sections, we describe how we used sketching, scenario development, and related material resources to explore and critically consider some possibilities given form by this design space, of consuming experience in theme parks.

\section{CONCEPT SKETCHING}

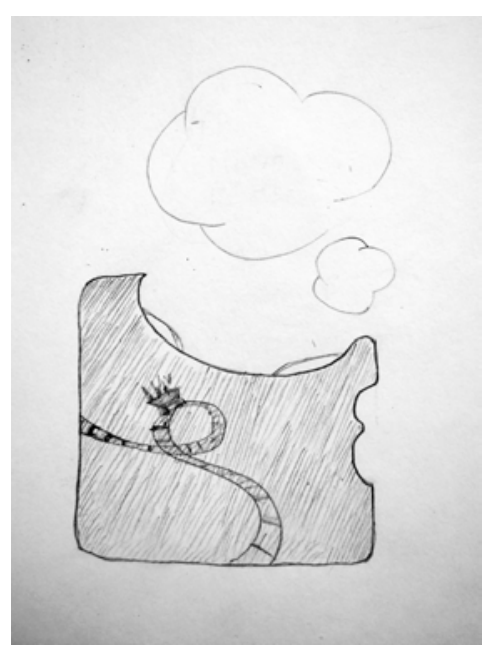

Figure 1. Conceptualising the cocreation of souvenirs by the park and its visitors. Image: A. Durrant.
Our field studies and interviews generated socio-technical insights about how visitors experience a theme park and orient to its technologies and souvenir services (see Durrant et al 2011). These insights provided the original impetus for the design work, based upon four 'sensitising' considerations. One was to reconceptualise the materiality of souvenirs to incorporate digital media. A second was to critically explore what it means to conceptualise the theme park as an anthropomorphised intelligent park system with discrete agency for intervening in visitor activities (Figure 1). A third was for visitors and the park systems to collaborate in the co-creation of souvenirs. A final consideration was to explore the notion that visitor interactions may be captured as a digital trail of activity, or 'contextual footprint', and be leveraged in design. These considerations were initially discussed, critiqued and developed at a design workshop that engaged an interdisciplinary group (c. 20 people) of colleagues and representatives from our industry partnerships. The workshop provided critical perspectives to motivate the next stage of the design process.

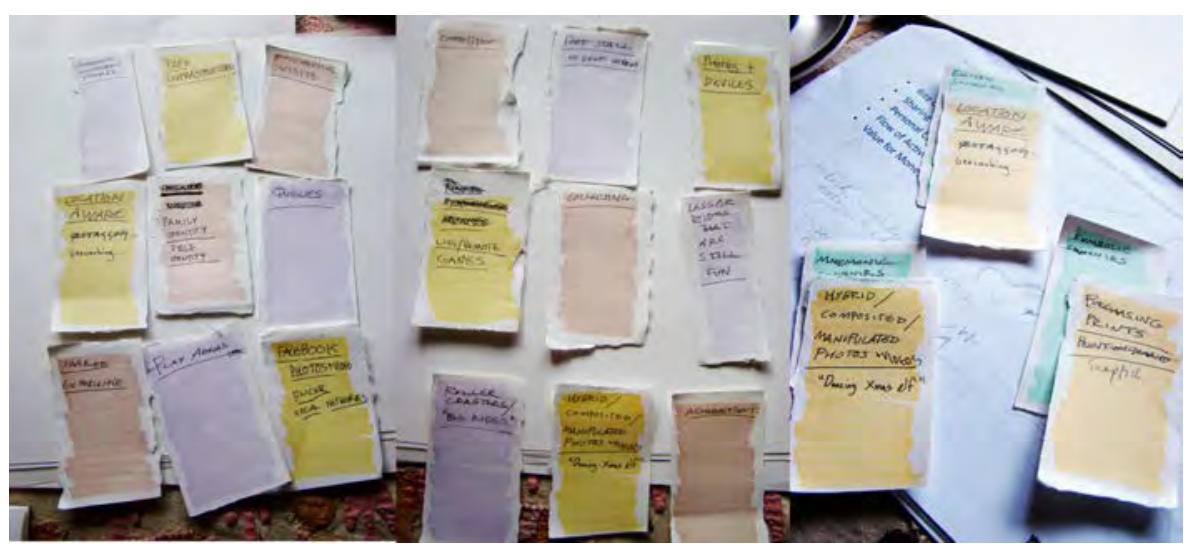

Figure 2. Making Ideation Cards to support concept sketching. Image: A. Durrant.

Two of this chapter's authors and the designers in our team (Durrant and Golembewski) then used a card-based ideation technique, as detailed in Golembewski and Selby (2010), to build on the workshop outcomes. We made a bespoke deck of cards grounded in the aforementioned considerations. Each suit in the deck was colour-coded to represent a category or axis of thinking, each depicting content about a different feature of the design space - type of park visitor, visitor activities, technologies, avenues for engaging with visitor data (Figure 2). Different coloured cards were then combined to create new design briefs, serving to think through 'instances' of park activity and establish meaningful constraints for the designers to respond to. A number of novel conceptual designs were rapidly 
generated and informally critiqued; these were hand-drawn and rendered in provisional form. It's worth emphasising that these designs were not envisioned as solutions to problems per se, but rather as a means to open up and give form to spaces of possibility and speculation (Dunne and Raby, 2013; Gaver 2012). A particular strength of the card technique was that it could be used to explore multiple and alternative design situations (Tohidi et al., 2006). This ideation activity guided the team to consider the full breadth of the design space of possibilities, also generating loose working taxonomies of relevant factors to consider.

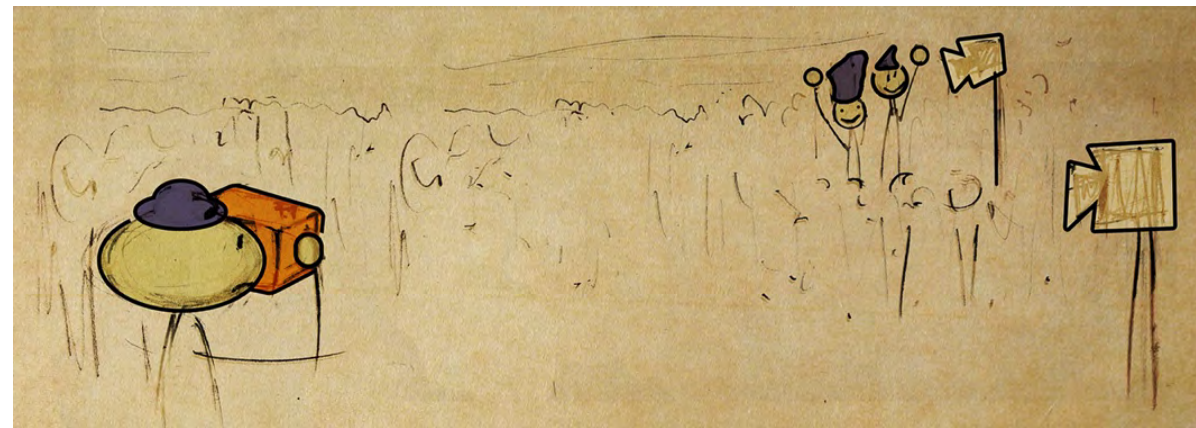

Figure 3. Early sketch of characters interacting with a design called Magic Cam in The Park.

Early on in this process we realised that it worked well for us to 'place' or arrange these sketched designs not just in the instances of park activity, but also their interrelation in the context of an imaginary theme park setting, hereafter referred to as The Park. Fictional features and branding were inspired and grounded by the field insights from Alton Towers. Through hand-drawn sketching we imagined how a group of visitors might encounter and interact with each design, and with designs in conjunction with each other (Figure 3). This led us to create fictional interaction scenarios for our designs, as experienced by imaginary visiting parties. We adopted layout structures from sequential art to develop these scenarios (McCloud 2001). Sequential art has been increasingly drawn upon in creative and visual approaches to HCI inquiry and project dissemination, in especially in the comic book format, with demonstrable impact (e.g. Dykes et al, 2016a; Dykes et al, 2016b; Rowland et al 2010; Sousanis, 2015), and it was a logical extension of our hand-drawn mode. As we considered the physical affordances of collaborative work with sequential art sketches, we arrived at the notion of assembling all of the scenarios in a 'picture book' format (Nikolajeva and Scott, 2000). We oriented to the picture book as a developing document made manifest in both digital form and print, that brought the scenarios together into an overarching, polyphonic narrative of 'A day at The Park'.

\section{CHARACTER-DRIVEN SCENARIOS}

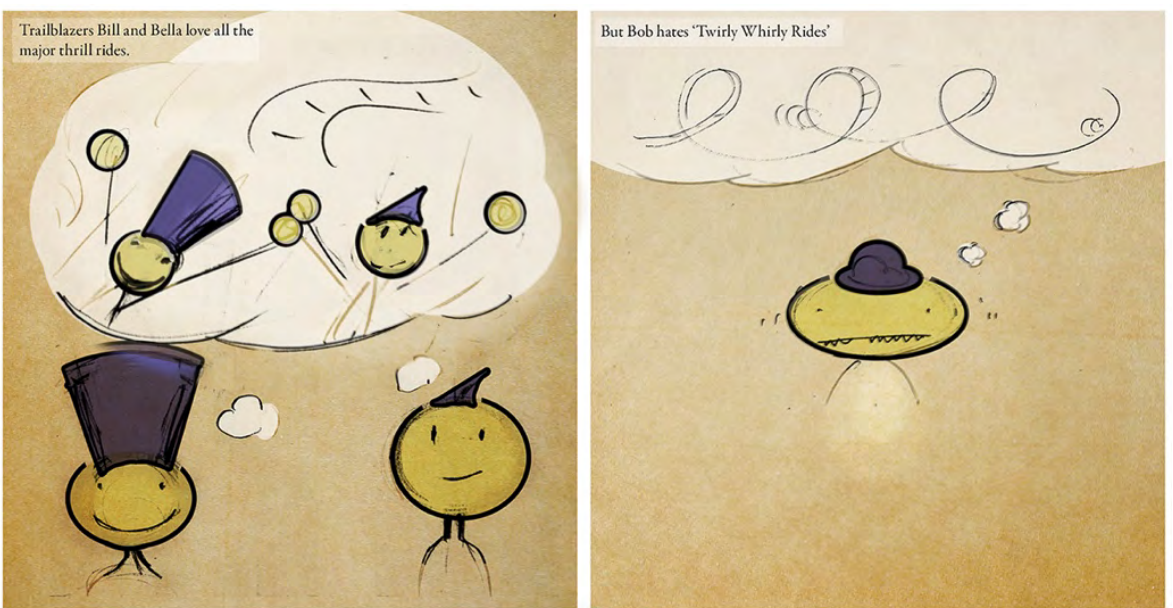

Figure 4. Characters Bella, Bill, and Bob, depicted as a visiting group of friends.

The picture book formed a critical-reflexive tool in an ongoing, iterative process of 
sketching and sense making that was grounded in the field insights. This process was realised in two ways. First, developing the visual format and storyworld formed a rich exchange of ideas and understandings. Second, after the book was produced it prompted researcher-stakeholder dialogue.

The Park formed a diegesis for the scenarios to unfold in, and was depicted with fictional flagship rides in three imaginary zones, populated with characters visiting in three separate groups. We continued to be inspired by the literary devices of the polyphonic novel in our scenario development. Central to this genre is that the characters and their actions are not determined by their situation, rather they are brought together in dialogue to determine plot action. Characters thus drive the narrative development of the scenario. The character creation was inspired and informed by the real-world participants in our previous research, including their behaviours, socio-economic and ethnic backgrounds, and intra-group relations. They formed, in many ways, personas, because they were representative of our research population and the visitor demographic of Alton Towers. But they were also distinct as characters, interacting in ways that were open to the imagination. Significant for our account herein, our engagement with the characters fostered our empathetic connection as designers with theme park visitors-as-technology-users (Blythe and Wright, 2006; Wright and McCarthy, 2005). We also responded to Nielsen's (2002) critique of personas that emphasises the importance of developing emotionally relatable characters in scenarios.

Let us briefly introduce these characters, visiting The Park in groups. One group comprises three friends: Bill, Bella and Bob (Figure 4). Bob is the fearful rider; roller coasters make him feel ill. A different group comprises a nuclear family: Jo and John Jones, and their children Jack (aged 10 years) and Jane (aged 7). Jack is a thrill-seeker and keen Park-goer, whilst his father is fearful of 'coasters. A third, extended family group is composed of Sam Smith, his father Simon, and grandfather Saul. 'Park' is an anthropomorphised theme park system infrastructure and has considerable agency as a character (Figure 1), looking for opportunities to engineer fun and serendipitous moments in visitor interaction that promote a certain visiting experience. As these characters developed, we allowed their traits and behaviours to result in certain situations and events, hence referring to character-driven scenarios. For example, the interpersonal dynamics between Bill, Bella and Bob changed during the storyboarding process. The decision to ascribe character names that started with the same letter within each visiting group was made to help readers manage the complexity of the storyworld and enable surface-level as well as deeper levels of engagement - deemed important for differing engagement contexts. 


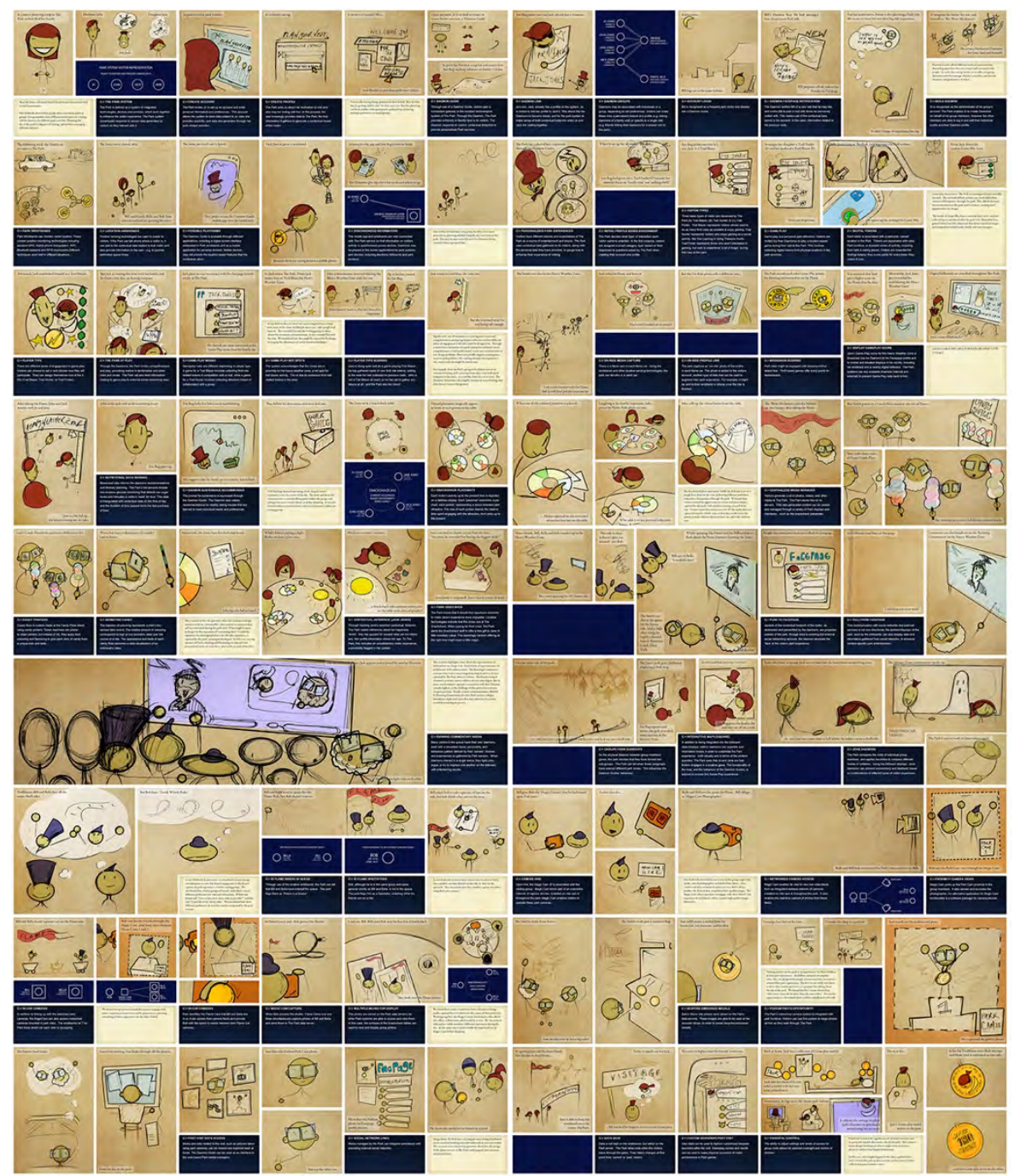

Figure 5. A bird's eye view of the picture book spreads.

The inquiring function of the scenarios was reflected in the graphical rendering of their content. We set out to create multivoicedness in the narrative (Wright and McCarthy 2005); each scenario was depicted through multiple 'voices' (Figure 5). First, a visitor perspective captured unfolding visitor interactions and experiences at The Park, through hand-drawn cartoons. Second, a notional 'Park system' perspective depicted a symbolic reading of sensed visitor interaction with Park infrastructure, accompanied by text boxes describing how the Park was making sense of visitor interaction. In developing The Park perspective, we considered how it might interpret and draw inferences from visitor interaction. Third, the researchers' perspective served to ground the fictional narratives in the original field findings, depicted as descriptive notes and, at times providing additional context for the other perspectives. Multivoicedness was further expressed through: (a) the different characters represented within the visitor perspective; (b) the combination of symbolic language and textual account within the Park perspective; and (c) through the multiple voices of the design team from the researcher perspective. This potential of the sequential art medium for expressing different perspectives has also been recognised by Dykes and colleagues, who, in a recent account of a making process that was rendered as a comic, distinguished the lead author's voice through his depiction as a character (2016b). 


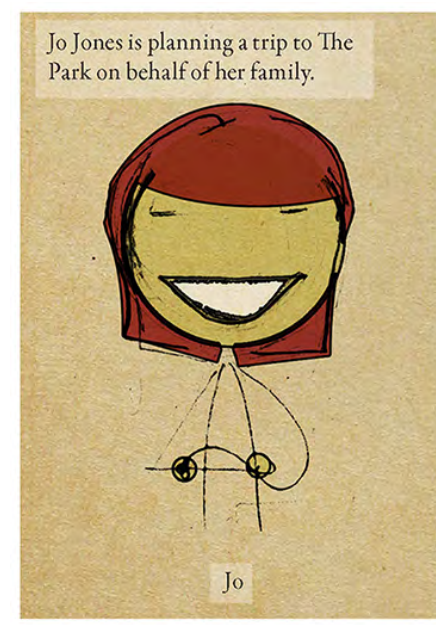

Meet the Jones, a fictional family based on our interactions with research particpants.

Our fieldwork showed that people often visit theme parks in groups. Group members have different motivations for visiting and the desire to do different park activities. Planning the day at the park is a big part of visiting and involves managing different interests.
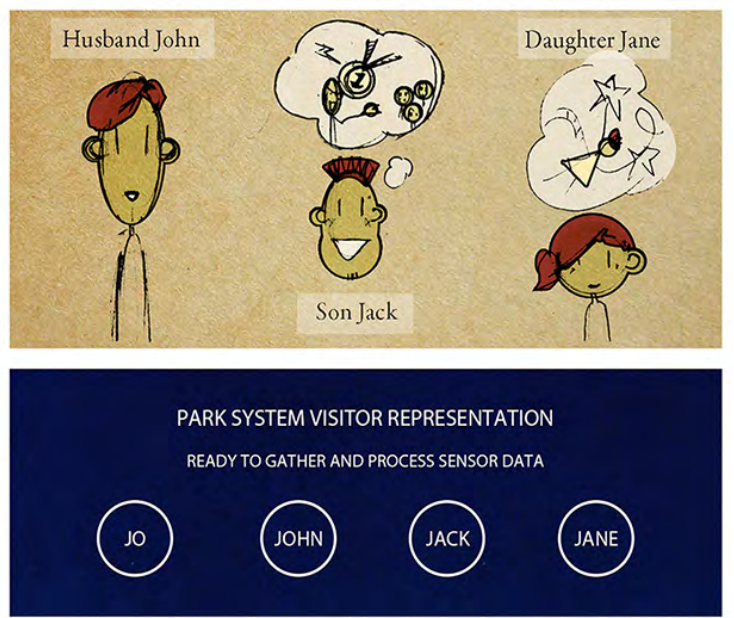

C:> THE PARK SYSTEM

The Park is defined as a system of integrated technologies, devices and services, which work together to enhance the visitor experience. The Park system dynamically responds to sensor data generated by visitors as they interact with it.

Figure 6. Storyboard detail shows the rendering of multiple perspectives on the scenario.

Our choice of sequential art afforded the presentation of these three perspectives with clarity and comprehensibility (Figure 6). As the three perspectives developed in conceptual terms, we started to combine hand-drawn paper sketches with computergenerated illustration and formatting, scanning drawings and overlaying and juxtaposing the scans as digital media aided by Adobe Creative Suite applications (Photoshop, Illustrator, and InDesign). In the developing digital layouts, the handdrawn aesthetic of the visitor perspective became visually distinct from the Park perspective to communicate different 'voices'. The researcher perspective became visually distinct from the perspectives through use of a different colour palette, stylisation and typesetting (Figure 6). As the graphics developed for the storyboards, we oriented to this researcher perspective as if it formed an interjection or reflective pause-point in the narrative proceedings of the other two perspectives (Figure 5).

As storyboarding continued, we further introduced templates for the layouts, which streamlined our workflow and enabled us to keep focused on the narrative possibilities afforded by interactions in the storyworld. Retaining digital layers, we could rapidly edit text in the storyboards along with other visual elements. The flexible workflow ensured that our working documents remained provisional in form, and open to a degree of revision and redrawing.

\section{SOUVENIR CONCEPT SKETCHES}

We now turn to present extracts from scenarios that were included in the picture book for this project, to illustrate our account herein. Captured here are three of the eight design concepts and two of the three fictional visiting groups. Scenario content has been adapted for the page formatting of this chapter, and is depicted in indented prose supported by figures. The visitor perspective is italicised, the Park perspective is prefixed by a $(\mathrm{C}:>)$ command line prompt, and the researcher perspective notes are underlined). For more detail on the designs see Durrant et at al 2011a.

\section{Daemon Guide}

This concept introduces the idea of a customizable virtual agent or bot, providing visitors with a personalized means of interacting with the Park and its systems that is tailored to individual preferences and linked to previous experiences of visiting. The name Daemon references both the entities (daemons) featured in Phillip Pullmans' 
'Dark Materials' trilogy (Pullman, 1998), and also the constantly running background tasks found within multitasking computer systems.
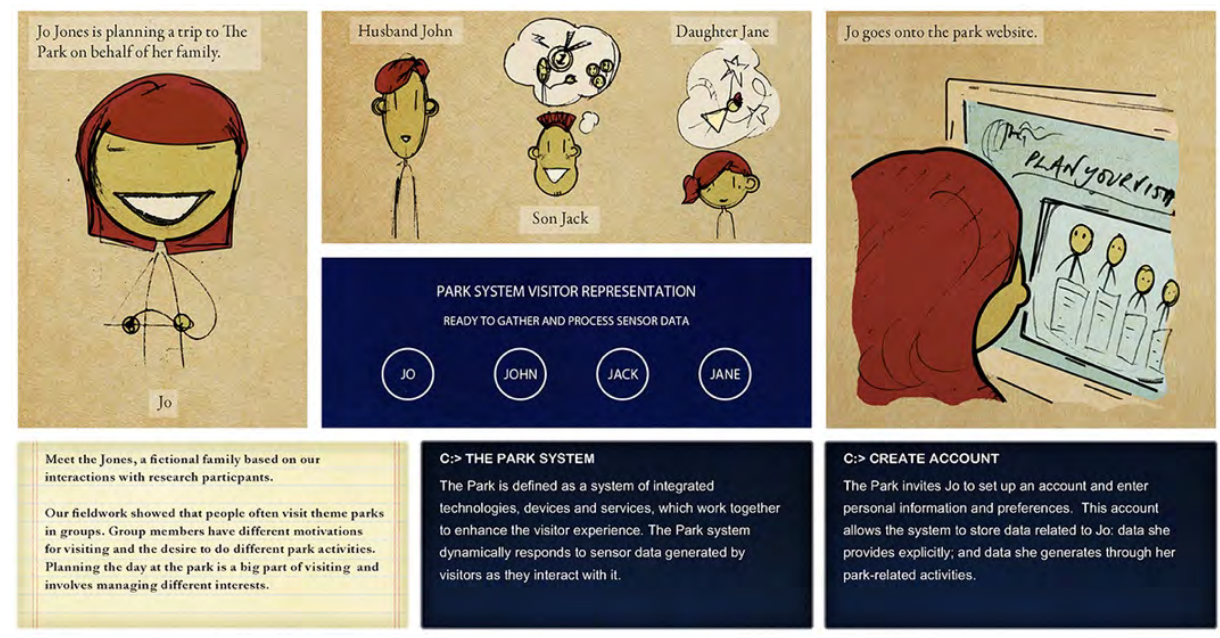

Figure 7. Example of picture book page layout.

Jo Jones is planning a trip to the park on behalf of her family. Jo goes onto The Park's website.

Our fieldwork showed that group members have different motivations for visiting. A key challenge when planning a visit was to manage multiple in-group interests and capture individual experiences alongside shared ones.

C: > CREATE ACCOUNT. Park invites Jo to set up an account and enter personal information and preferences. This account allows the system to store data related to Jo: data she provides explicitly; and data she generates through her Park-related activities. Jo is given a unique identifier, associated with a profile that she creates.
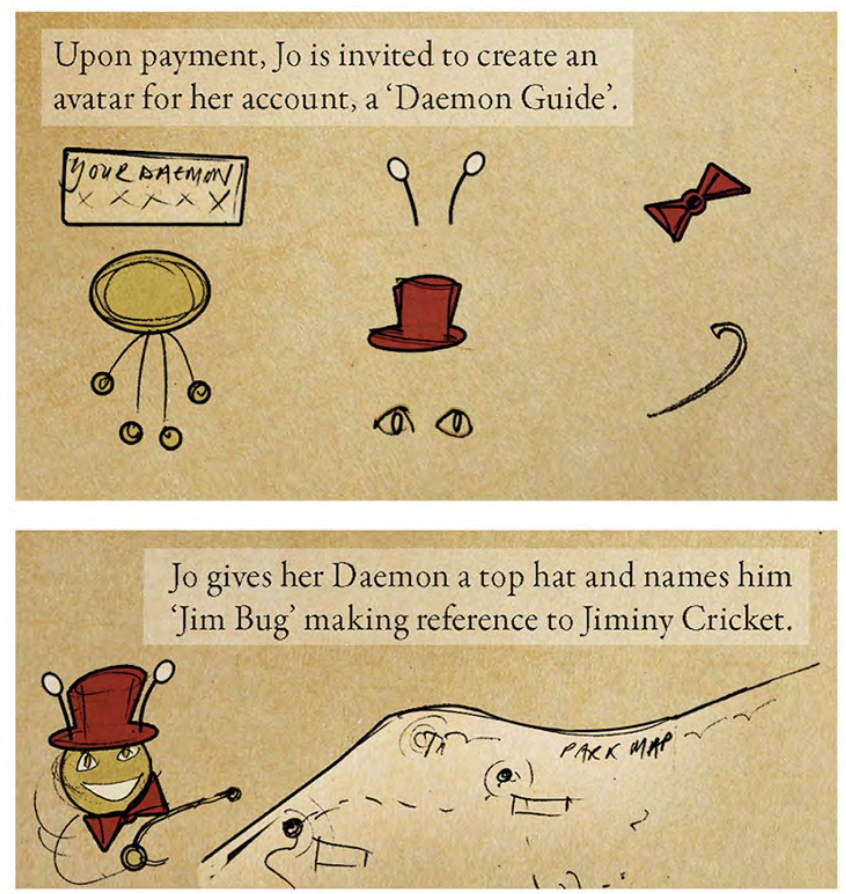

Figure 8. Storyboard detail depicting the visitor perspective. 
Jo is then invited to create a Daemon Guide for her account. Jim-Bug asks Jo about her motivation to visit and who may be visiting with her. Jack already has a Park profile, and a Daemon Guide called Pirate Jones. Jo is invited to link her profile to her son's profile.

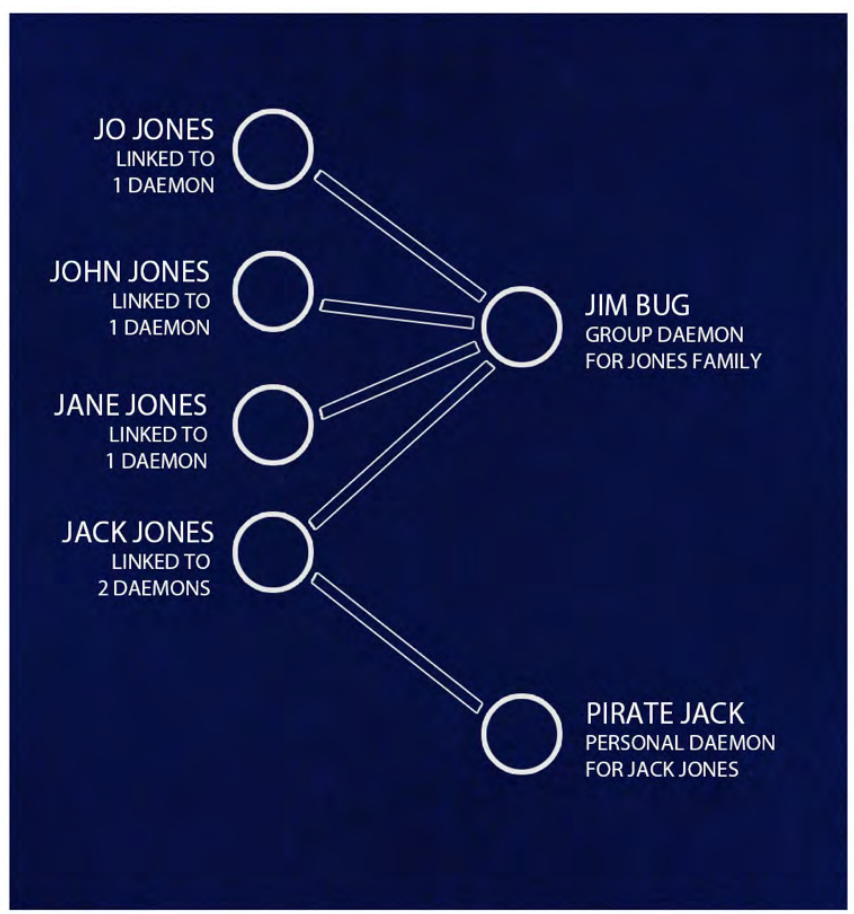

\section{C:> DAEMON GROUPS}

Daemons may be associated with individuals or a group, depending on set preferences. Visitors can make these links a permanent feature of a profile (e.g. linking daemons of a family unit) or specific to a single visit (e.g. friends linking their daemons for a shared visit to the park).

Figure 9. Storyboard detail depicting the Park perspective.

Across town, Bill proposes a visit to the Park with his friends, Bob and Bella. Bill is recognised as a frequent Park visitor and already has a Daemon Guide. Bill's Daemon uses Facepage, a social network site, to notify him about a new ride and invites him to visit.

As the scenario progresses, more aspects of Daemon Guide creation are explored. The storyboards reflect how the social dynamics of visiting and repeat visiting noted in the field findings motivated the technical and logistical aspects of Daemon Guide interaction (Figures 8 and 9).

The next week, the Jones arrive at The Park, followed shortly after by Bill, Bob and Bella.

C: > LOCATION SENSING. Upon arrival at the entry gates, position-sensing technologies locate Park's visitors. Park provides them with tailored information - e.g. provide estimated queue times or signpost nearby attractions. 


\section{Snackshacks}

The group consumption of refreshments in The Park provides a context for the social consumption of souvenirs. Snackshacks cater for this. Visitors view, share and triage park-captured media on interactive table-tops whilst consuming refreshments.

\section{C: > DAEMON SUSTENANCE RECOMMENDER}

Upon leaving the Heavy Weather Zone, the Jones' family reunite. Whilst Pirate Jack is excitable, John looking pale needs something to eat. Jim Bug suggests that the Jones' visit a nearby Snackshack on site.
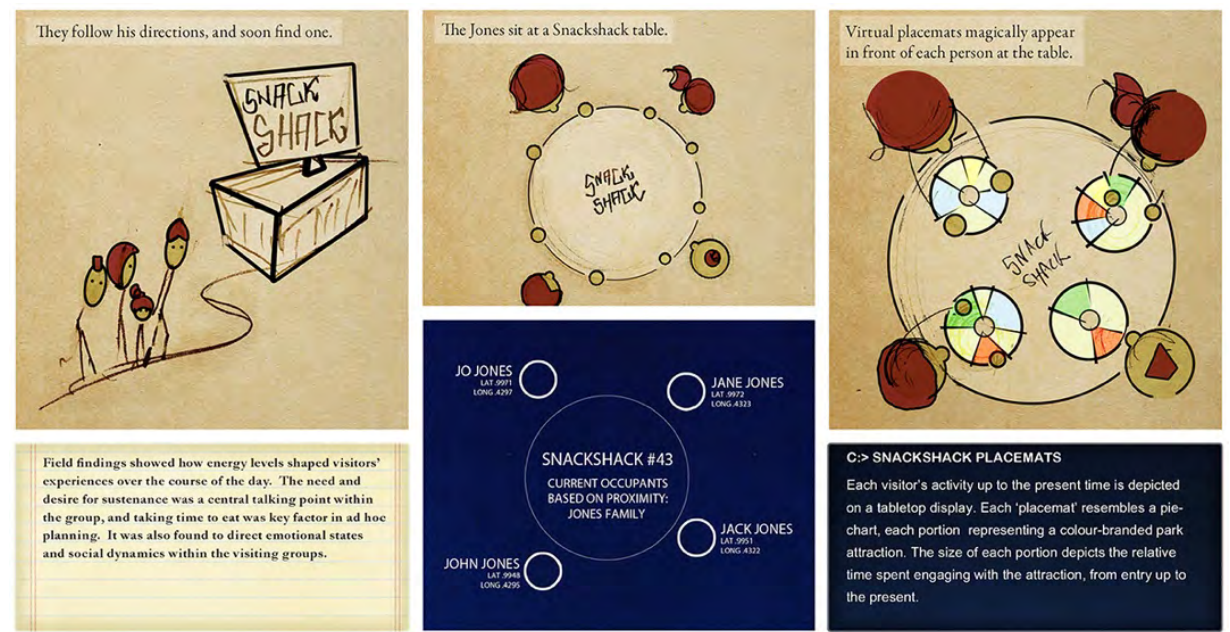

Figure 10. Picture book spread depicting Park and Snackshack designs.

Field findings showed how energy levels shaped visitors' experiences over the course of their visit. Sustenance was a key talking point between visitors, and taking time to eat together was a factor in ad hoc planning. It was also found to direct emotional states and social dynamics.
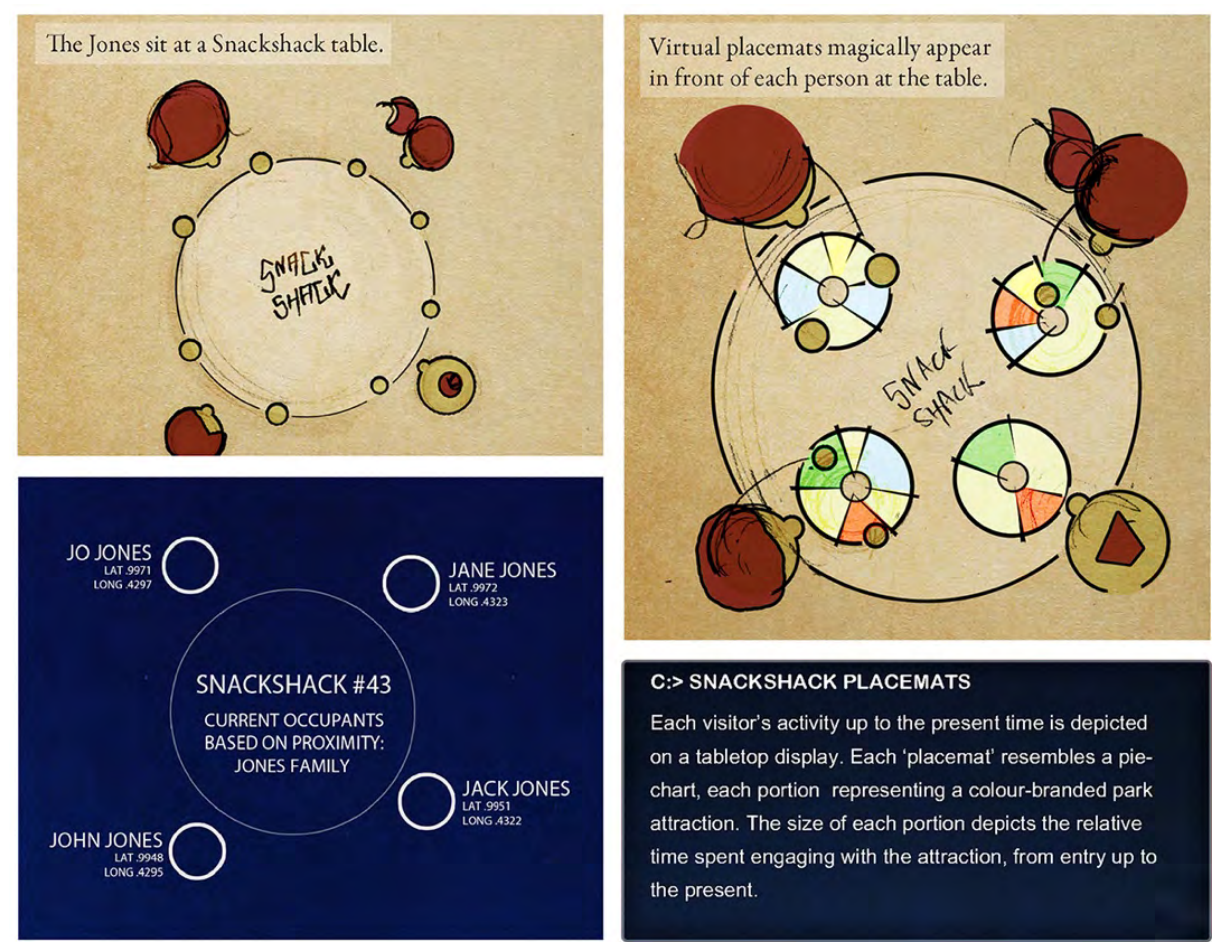

Each visitor's activity up to the present time is depicted

on a tabletop display. Each 'placemat' resembles a piechart, each portion representing a colour-branded park attraction. The size of each portion depicts the relative time spent engaging with the attraction, from entry up to the present.

Figure 11. Storyboard detail: on visitor and Park interpretations Of activity. 
The Jones' sit at a Snackshack table. Virtual placemats magically appear.
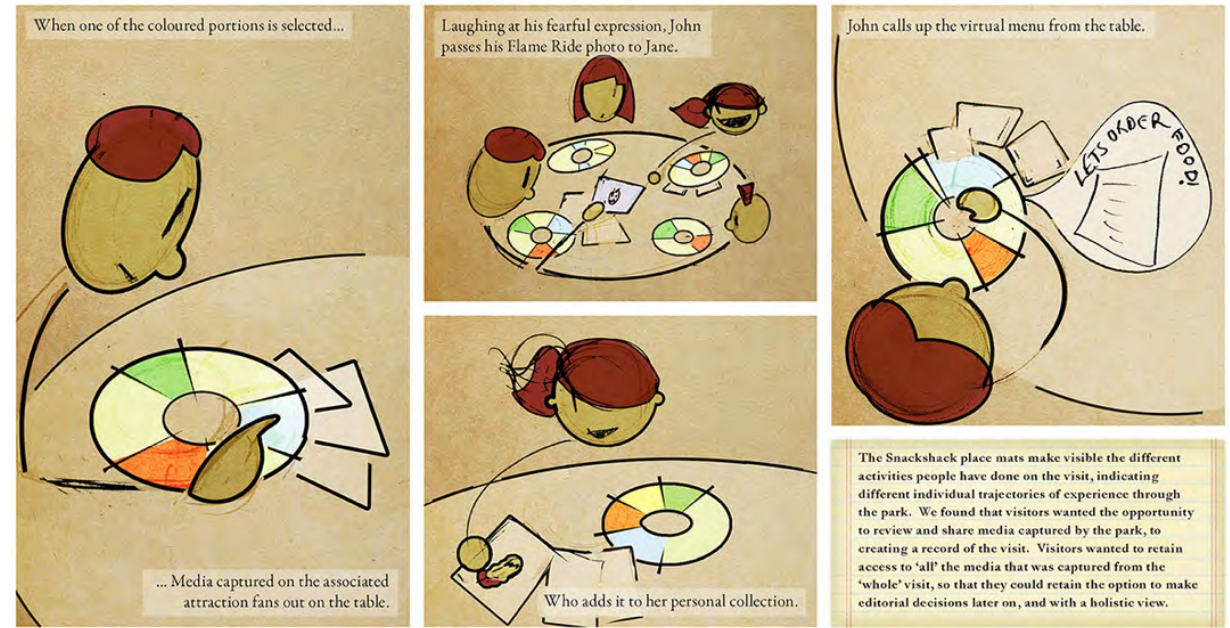

Figure 12. Picture book spread: on creating and consuming souvenirs in The Park.

C: > SNACKSHACK PLACEMATS: Each visitor's Park activity up to the present time is depicted on a table-top display. Each 'placemat' resembles a pie chart, the size of each portion representing the relative portion of time spent with a colour-branded attraction since entry.

When Jane presses one of her placemat portions, media captured around the associated ride fans out on the table. Jane laughs at the fearful expression on her father's face, from being in the Heavy Weather Zone. She adds one of his photos to her personal collection.

The Snackshack place mats make visible the different activities people have done on the visit, indicating different individual trajectories of experience through the park. We found that visitors wanted the opportunity to review and share media captured by the park, to create a record of the visit. Visitors wanted to retain access to all the media that was captured from the whole visit, so that they could retain the option to make editorial decisions later on, and with a holistic view.

Figure 13. Storyboard detail depicting the researchers' perspective.

C: > CENTRALISED MEDIA MANAGER: The Jones' generate a volume of media at The Park on personal mobile devices, which can be automatically uploaded and stored on Park servers, along with Park-generated media, and then viewed and edited on Park interfaces. 

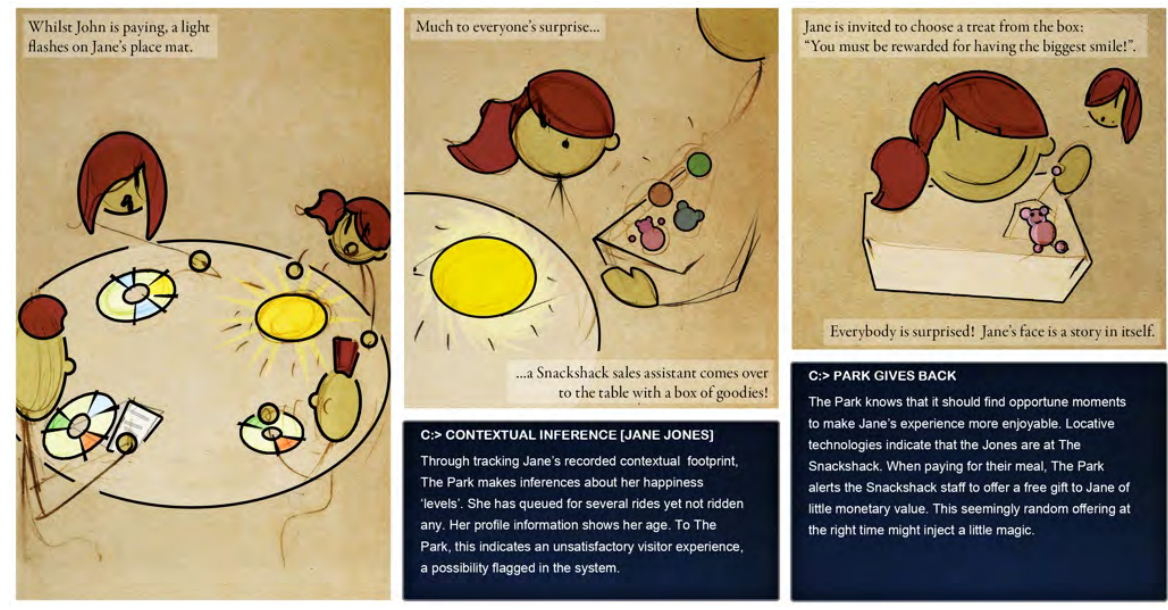

Figure 14. Picture book spread depicting Park interacting with its visitors.

C: > CONTEXTUAL INFERENCE [JANE JONES] Through tracking Jane's recorded contextual data footprint, Park makes inferences about her happiness 'levels'. Jane has queued for several rides but not ridden any. Her profile shows her age. Park alerts the Snackshack staff to order Jane a free gift.

\section{Magic Cam}

Magic Cam is an integrated in-park photography system that leverages an extensible network of locative technologies and resident cameras (Park Cams) distributed across the site (e.g. in queues, ride cars). A key interface is a handheld viewfinder called Magic Cam, with a camera selection dial and a shutter button. Magic Cam users can operate the Park Cams and view live video feeds from across this camera network, including those located in inaccessible places such as on rides. It also enables the real-time capture of photos from these feeds (see Figure 3 above). Upon hire, the Magic Cam ID is associated with the visiting group.

\section{C: > ID FLAME RIDERS IN QUEUE}

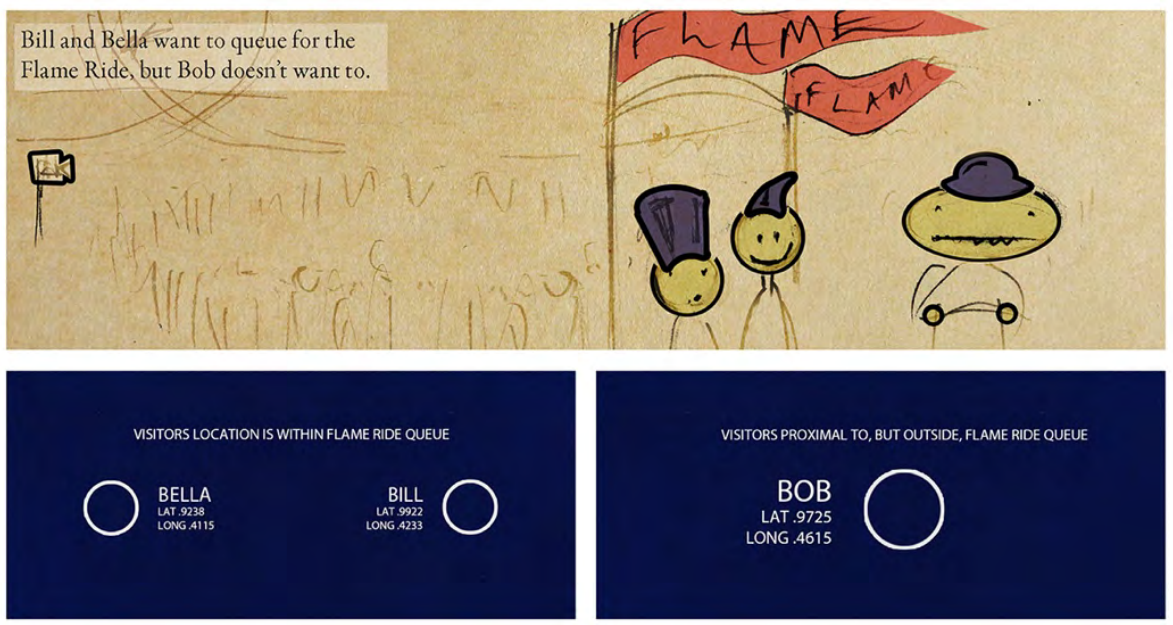

Figure 15.Picture book spread depicting Park making contextual inferences.

Bill, Bob and Bella approach the Flame ride in the Heavy Weather Zone. Bill and Bella want to queue for the Flame Ride, but Bob doesn't want to. He's getting a headache.

In our fieldwork we found that visitors were frustrated when they couldn't see 
their friends on a given ride, and share in the thrill. This also meant that they couldn't capture the riders using their personal cameras.

Bill gives Bob a Park Magic Cam that he hired upon Park entry, and asks him to take on-ride photos on his behalf. Bob obliges as 'Magic Cam Photographer', whilst Bill and Bella join the queue for The Flame. Whilst in the queue, they look into one of the Park Cams and wave to Bob. Bob sees the Park Cam 1 view through the Magic Cam viewfinder.

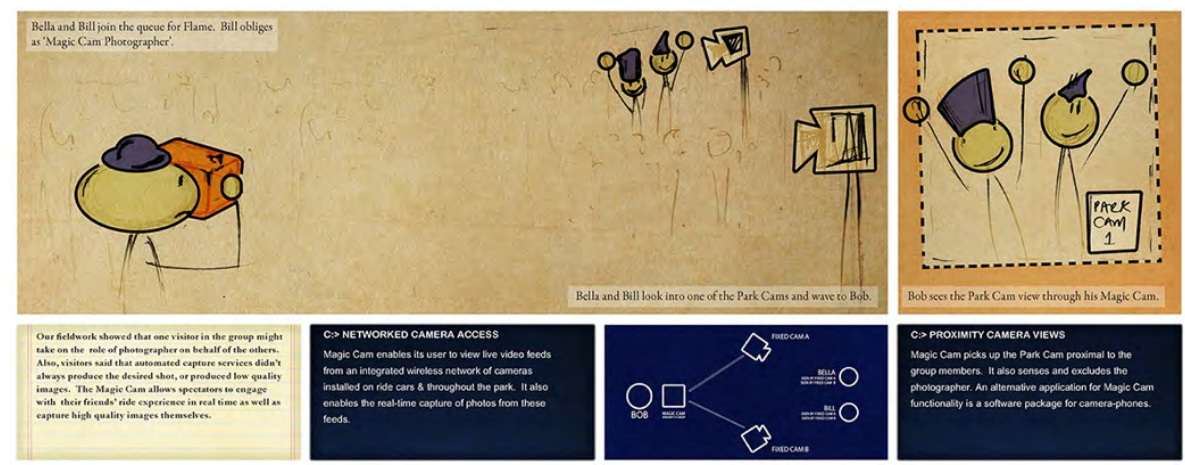

Figure 16. Picture book spread depicting multiple perspectives from Park and its visitors.

C: > PROXIMITY CAMERA VIEWS: Magic Cam senses the Park Cam proximal to group members, in this case, Bill and Bella. It also senses and excludes the photographer, Bob.
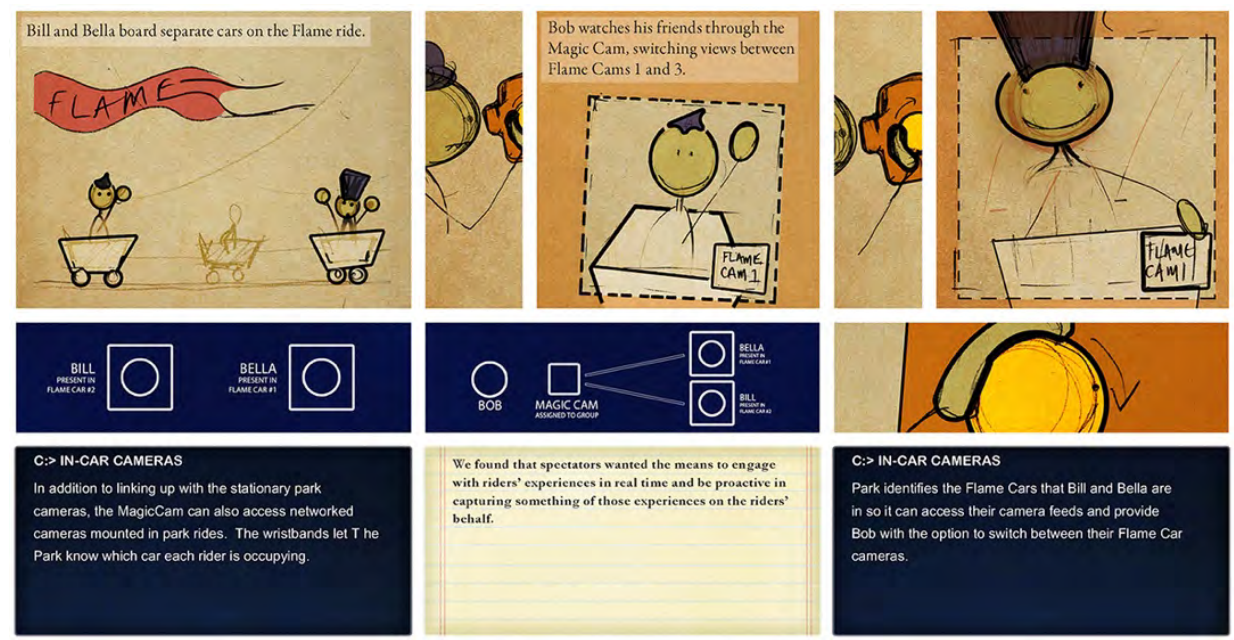

Figure 17. Picture book spread: on co-creating souvenirs between visitors and The Park..

Bill and Bella board separate cars on the Flame ride.

Location sensors let Park know which car each rider is occupying. We found that spectators wanted the means to engage with and capture riders' experiences in real time. 

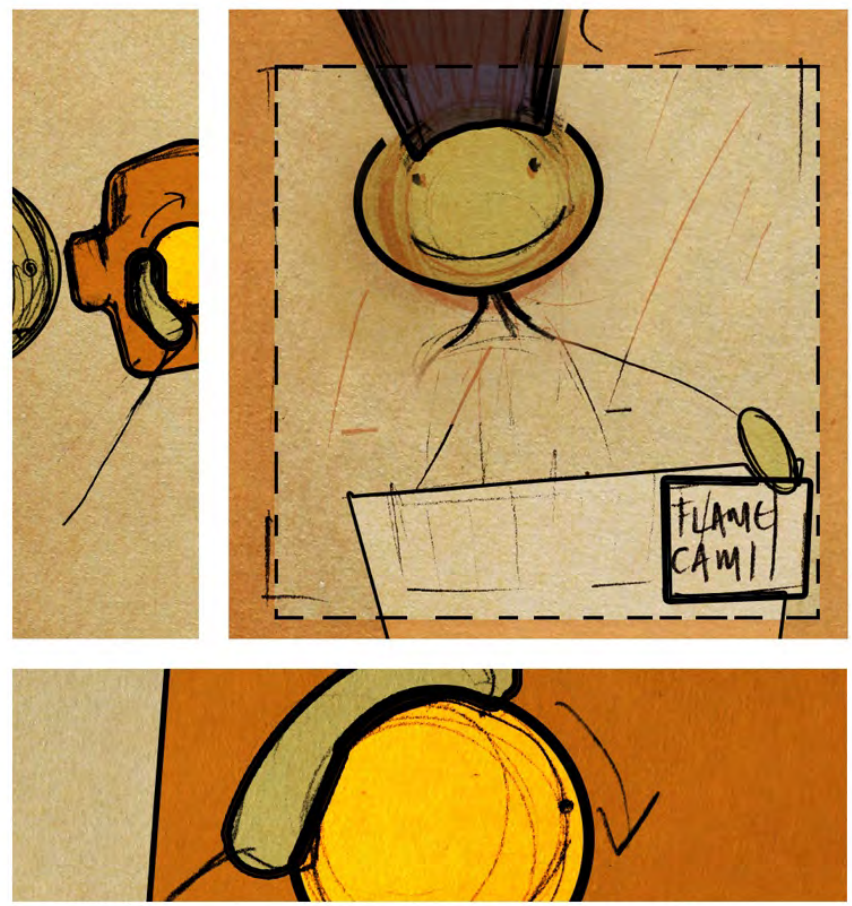

\section{C: > IN-CAR CAMERAS}

Park identifies the Flame Cars that Bill and Bella are in so it can access their camera feeds and provide

Bob with the option to switch between their Flame Car cameras.

Figure 18. book spread detail: on co-creating souvenirs.

By turning the dial on the side of the Magic Cam, Bob can switch between the different views of Bob and Bella. Bob finds these views pretty exciting, although still feels frustrated.
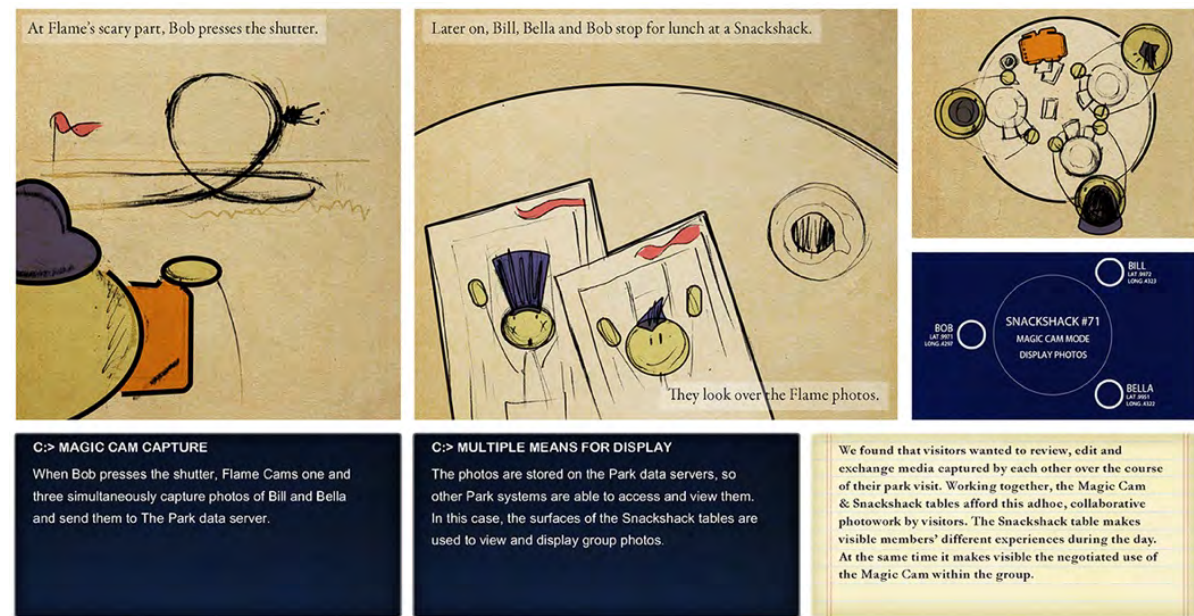

Figure 19. Interacting with multiple designs in The Park.

At Flame's scary part, Bob presses the Magic Cam shutter. 
C: > MAGIC CAM CAPTURE: When Bob presses the shutter, Flame Cams One and Three simultaneously capture photos of Bill and Bella and send them to the Park servers.

Later on, Bill, Bob and Bella stop for a drink and look over the Flame photos.

We found our real-world visiting groups wanted to review, edit and exchange media captured within them over the course of their park visit. Magic Cam and the Snackshack tables afford this collaborative photowork, and the in-park consumption of photos and video media.

C: > MEDIA ARCHIVING: Data is not kept on Park servers. Park takes note when visitors leave through its gates.

When Bella was looking through her media archive, she came across only two photos of Bob from the day at The Park. In one of the photos he was captured pulling a face at her behind her back. This must've been taken on accident by one of the Park Cams. Viewing this photo made Bella angry and she hasn't spoken to Bob since.

C: > CUSTOM SOUVENIRS: Post-visit, visitors can fashion bespoke souvenirs using online services. Daemons use contextual tags to auto-generate media stories from one or more visits.

\section{ENGAGING DESIGN THROUGH THE PICTURE BOOK}

We've described how the picture book spreads afforded the expression of polyphony within the character-driven scenarios (e.g. Figures 10 to 14) and, in turn, within our design space (e.g. Figures 15 to 19). However, as introduced above, we found the iterative sketching process useful for establishing dialogical understanding between the members of the research team. The sequential art mode helped us acknowledge, maintain, and integrate our personal contributions within our design process. We each identified with particular, complementary, aspects of the process so that none of us had a distinct authorial voice. The two designers in the team assumed roles in the production of the storyboards, with one preparing the original hand-drawings (Durrant) and the other developing the digital renderings and inking (Golembewski). The spatial arranging of the storyboards was deeply collaborative. Tangible drawings and print-outs afforded the collaborative organising of content into frames, storyboards, and page layouts. In this activity we worked through characters' encounters with a given design element, and their interactions with its functional features - whether serendipitously or in pursuit of particular goals. Our workflow encouraged this inquiry whilst ensuring that the storyboards had visual coherence and that the production work was efficient to maximize our time for ideation. The experience of sketching-as-inquiry was constructive because it felt like our process flowed in the layering of material forms and resources that we shared to-hand.

Shifting from our 'researcher' engagement with the book, we may also reflect on how the multi-perspectival visualisations also enabled dialogue with the book's other readers, once it was produced: the members of our wider research team, and the project partners and stakeholders. As Scott McCloud (2001) and others including Rowland et al (2010) and Dykes et al (2016a, 2016b) have noted, a valued feature of the sequential art form is that it is accessible to multiple levels of reading. The pictorials are widely accessible, and, technical or academic language aside, they communicate widely and at a glance. There is a relatively linear reading of the book, considering the instances of activity as they unfold in time, from page to page. Alternatively, a reader may choose to follow one perspective more closely, or jump across pages and storyboards to analyse a particular design in a different context of use. The visual coding of perspectives was intended to aid such alternative readings. As also noted by McCloud (2001), the gaps between the panels in a storyboard 
become almost as important as the panels themselves; the careful pacing and layout of the designs enabled the inference of storyworld elements between scenes. This was intended to support our readers' imaginative exploration of the design space as it had supported ours when we developed the book.

The picture book was circulated, in both digital and print form, to others in the wider project team including colleagues working in business and management studies. It was a resource in round-table gatherings, to consider strategic design implications and opportunities for business modelling around new forms of souvenir consumption in the entertainment industries. These colleagues reported finding the book valuable for giving form to near-future design directions, and making 'real' and 'consequential' the concepts and people's interactions with them. Participants described how the characters felt more 'alive' and 'relatable' than personas because of their closeness in representational terms to the individuals who participated in our empirical studies; this was emphasised in the juxtaposition of the researcher voice and the visitor voice in the storyboards. They felt that they could link the empirical instances to possible interactions in the storyworld, in a way that enabled them to anticipate character reactions. This also meant that the designs were open to critique and iteration. Indeed, this sense of unfinalisability was also communicated through the graphics; the original hand-drawn sketches were kept visible behind layers of digital rendering, which was picked up in the round-table discussions.

We also presented the scenarios to our partners at Merlin for their consideration. In this context the picture book usefully enabled a level of nuance and complexity about The Park to be communicated to a large number of people in a very short time. Certain features of a system or service could be considered with quite precise technological configuration. The printed book form afforded straightforward navigation and glanceability, aiding group discussion. One tension with presenting the content in book form to industry partners was that it risked elevating the designs to potential product proposals. However, the provisionality of the designs, reinforced by their sketched rendering, implied that design thinking and envisioning in the conceptual space was agile and open to ongoing development, a valued feature of the generative 'research through design' endeavour (Gaver 2012).

\section{PICTURE BOOK FOR PROTOTYPING}

Having developed the conceptual designs, and critically discussed them, we were interested to select certain features and functions to develop further, prototype, and deploy back in the 'real world' of Alton Towers theme park, for the participants from our original field studies to experience. Based on the wider team and stakeholder engagement, we drew out particularly interesting 'design interactions' and 'instances of activity' to synthesise. We subsequently developed functioning physical prototypes of aspects of an envisioned souvenir service called 'Automics' (see Durrant et al $2011 \mathrm{~b}$ for a full account of this prototyping work).

The Automics service itself was based on a smartphone application (for the Android platform) that was designed to support souvenir co-creation. The app provided templates for its user(s) to arrange a montage of provided visual media, autocaptured by the existing park systems, and personally captured on the smartphones of visiting groups. The design of this service was only partially prototyped and implemented: critical 'user touchpoints' with functioning features were built at 1:1 scale for field deployment at Alton Towers; other aspects of the service were nonfunctioning and were staged in the field using a Wizard of $\mathrm{Oz}$ method (Martin and Hanington 2012); and the proposed service as a whole, along with its integration into a bigger network of systems and park infrastructure was left as envisioned in the fictional Park of the picture book. The 'big picture' afforded by the book, of The Park as a socio-technical landscape, provided an important scaffold for designing Automics as an end-to-end service, with functioning features to respond to particular instances of activity - intersecting with trajectories of visiting (Durrant et al 2011b). 
A field evaluation of Automics, in turn, provided further experiential insight about potential models of souvenir consumption that speak to a digital economy of cocreating data-as-product. At the end of the project with the theme park, these new insights were brought together with the picture book content and the physical prototypes to deliver a set of understandings that were speculative and futureoriented whilst remaining empirically grounded. These deliverables, as an assemblage, offered concrete examples of possible worlds made human-scale, relatable, and remaining open to interpretation.

\section{CLOSING DISCUSSION}

In this chapter we have described how a creative design process furthered an interdisciplinary programme of research about cultural visiting mediated by pervasive interactions with personal data and personalised souvenirs. We have reported on a collaboration anchored around the sketching of design concepts embedded in fictional, character-driven scenarios and assembled in a picture book. We explained how the scenarios were developed from empirical insights and used by the project team to advance design understanding. Taken together, the scenarios have helped deliver strategic design implications for shaping socio-economic, infrastructural and human concerns in the theme park and related settings. The scenarios also scoped out a rich design space for novel forms of souvenir creation and consumption.

Returning to our three narrative strands, we consider the value of sketching as inquiry in the sequential art mode. This approach facilitated a rewarding collaborative process which fostered the flow of ideas and the envisioning of multiple perspectives on a set of designs and their potential instances of use. The literary devices we used, in particular those from the polyphonic novel, guided us in composing and speculating on the narrative of the scenarios and the storyworld of The Park. This approach offered us conceptual resources for designing to foster dialogue and provisionality around the creation of characters. Arguably, imaginary users and their interactions brought as much to the shaping of the design space as the real-world research participants did. Moreover, by exploring how non-human characters (e.g. systems) may be given voice and agency (Figure 12), we expand upon Dykes et al (2016a) to examine how a system might be made scrutable and accountable within a narrative.

Leading from this and returning to the second and third narrative threads, we have shown how sequential art afforded the visual presentation of multiple perspectives to convey complex human-data interactions - in this case with an extensible theme park infrastructure. We reiterate here that our conceptual designs were positioned as critical, speculative devices to foster ideation around instances of park activity, and possible near futures, by the partners and stakeholders in our research. We highlight the efficacy of the sketching and storyboarding for enabling the development and critique of concepts more rapidly and flexibly than may be possible with physical prototyping (Blythe 2014). We've also demonstrated how this conceptual work can be pursued in conjunction with physical prototyping and empirical studies.

Gaver has critiqued scenario use in HCI design processes, in particular suggesting that it may create a 'unitary vision' that closes down interpretation of how the designs may be used, evaluated, and further developed (Gaver 2011, p.1553). We argue that by developing characters inspired by our real-world participants, and allowing these characters to ground, inspire and direct the unfolding of design interactions in our storyworld, we could open up and entertain spaces for interpretation and empathetic connection. This potentially suggests a bridging between prototyping and the purely fictive scenarios explored by Blythe (2014) and others. However, as advocated by Blythe (ibid.), our theme park scenarios did provide a vehicle for the generation of narrative rather than design solutions. By juxtaposing and weaving through multiple accounts of sense making, and retaining layers of process and provisionality in our renderings - for example making visible 
the hand-drawn sketches under the computer graphics, we arguably sustained dialogical engagement around the various interactional elements in the design space and with the voices of those involved in the research.

Through our account herein, we hope to have demonstrated to our readers the rich potential of sketching in the sequential art mode to pursue creative and generative design inquiry. The methodological insights gained from this work have since been applied to another HCI research setting, in continuing efforts to critically explore ways to draw and design in conversation with empirical materials, and leverage the picture book format (Durrant et al 2015; Durrant et al 2016). In current and future work, we extend modes of inquiry and media into online video presentational platforms, opening up further spaces for dialogical encounter and polyphonic design.

\section{ACKNOWLEGEMENTS}

This research was funded by Horizon Digital Economy Institute (EP/G065802/1). The first author was supported in developing this work by The Leverhulme Trust (ECF-2012-642). We also thank our research partners Merlin Entertainments Group Limited and Picsolve International Limited, and we thank the staff at Alton Towers Resort along with our colleagues at Nottingham University for their participation in the project. We thank those who took part in the related field studies, for having fun at Alton Towers in aid of our research. We give special thanks to Steve Benford for directing the project 'A Day in the Park' and for supporting and discussing the picture book development. Image credits: the authors.

91

Mark A. Blythe, Andrew F. Monk, Kees Overbeeke and Peter C. Wright (eds.),

Funology: From Usability to Enjoyment, 91-100

(C) 2003 Kluwer Academic Publishers. Printed in the Netherlands. 


\section{REFERENCES}

Adams, J. A. (1991) The American amusement park industry: A history of technology and thrills. Boston, MA: Twayne.

Allen, S. (1999) Points+lines: Diagrams and Projects for the City, Princeton Architectural Press

Arnheim, R. (1995) Sketching and the Psychology of Design. In Margolin, V. \& Buchanan, R. (Eds.) The Idea of Design. MIT Press, Cambridge MA.

Bakhtin, M.M. (1981) The Dialogic Imagination: Four Essays. Ed. Michael Holquist. Trans. Caryl Emerson and Michael Holquist. Austin and London: University of Texas Press.

Bakhtin, M.M. (1984) Problems of Dostoevsky's Poetics. Ed. and trans. Caryl Emerson. Minneapolis: University of Minnesota Press.

Beer, D. and Burrows, R. (2013) Popular Culture, Digital Archives and the New Social Life of Data. Theory, Culture and Society. 30, 4, 47 - 71 https://doi.org/10.1177/0263276413476542

Bell, G. (2002). Making sense of museums: The museum as a cultural ecology. Technical Report. Intel Corporation.

Benford, S. and Giannachi, G. (2011) Performing Mixed Reality. The MIT Press.

Bleecker, J. (2009) Design Fiction: A short essay on design, science, fact and fiction, Near Future Laboratory, 29, http://tinyurl.com/jbbhvg4, (Accessed 09 September, 2015).

Blevis, E., Hauser, S., \& Odom, W. (2015) Sharing the hidden treasure in pictorials. interactions, 22(3), $32-43$.

Blythe, M. (2014) Research through design fiction: narrative in real and imaginary abstracts, Proceedings of the SIGCHI Conference on Human Factors in Computing Systems, pp. 703-712, ACM Press.

Blythe, M. A., and Wright, P. C. (2006) Pastiche scenarios: Fiction as a resource for user centred design, Interacting with Computers, 18(5), 1139-1164.

Brown, B. and Chalmers, M. (2003). Tourism and mobile technology. In Proceedings of ECSCW'03.(pp. 335-354). New York, NY, USA: Springer-Verlag.

Brown, B. and Juhlin, O. (2015) Enjoying Machines. MIT Press.

Buxton, B. (2007) Sketching User Experiences: getting the design right and the right design, Morgan Kaufmann.

Carroll, J. M. (2000) Making use: scenario-based design of human-computer interactions, MIT Press.

Cross, G. S., and Walton, J. K. (2005) The playful crowd: Pleasure places in the twentieth century. New York, NY: Columbia University Press.

Dunne, A. and Raby, F. (2013). Speculative everything: design, fiction, and social dreaming. MIT Press.

Durrant, A., Golembewski, M., Kirk, D. S., Benford, S., Rowland, D., and McAuley, D. (2011a) Exploring a digital economy design space in theme parks, Procedings of the Second Conference on Creativity and Innovation in Design, pp. 273-284, ACM Press.

Durrant, A., Rowland, D., Kirk, D.S., Benford, S., Fischer, J. and McAuley, D. (2011b) Automics: souvenir generating photoware for theme parks. In Proceedings of the SIGCHI Conference on Human Factors in Computing Systems (CHI '11). ACM, New York, NY, USA, 1767-1776. DOI: https://doi.org/10.1145/1978942.1979199

Durrant, A., Kirk, D.S., Benford, S. and Rodden, T. (2012) Pursuing Leisure: Reflections on Theme Park Visiting. Comput Supported Coop Work 21: 43. doi:10.1007/s10606-011-9151-1

Durrant, A., Moncur, W., Kirk, D., Trujillo-Pisanty, D. and Orzech, KM. (2016) On presenting a rich picture for stakeholder dialogue. In Proceedings of Design Research Society Conference (DRS 2016) DOI: $10.21606 /$ drs.2016.169

Durrant, A. C., Trujillo Pisanty, D., Moncur, W. and Orzech, K. M. (2015) Charting the Digital Lifespan: A Picture Book, Newcastle University, UK. ISBN: 978-0-7017-0250-2

Dykes, T., Blythe, M., Wallace, J., Thomas, J. and Regan, T. (2016a). RtD Comics: A Medium for Representing Research Through Design. In Proceedings of the 2016 ACM Conference on Designing Interactive Systems (DIS '16). ACM, New York, NY, USA, 971-982. DOI: https://doi.org/10.1145/2901790.2901821

Dykes, T. Wallace, J. Blythe, M. and Thomas, J. (2016b). Paper Street View: A Guided Tour of Design and Making Using Comics. In Proceedings of the Designing Interactive Systems Conference, ACM, Brisbane, Australia.

Eisner, W. (2008) Comics and Sequential Art, ISBN 978- 0-393-33126-4, W. W. Norton, London.

Elsden, C. Durrant, Abigail, C., Chatting, D., Kirk, D.S. (2017) Designing Documentary Informatics. In Proc. Designing Interactive Systems (DIS 2017). ACM, New York, NY, USA, (forthcoming). http://dx.doi.org/10.1145/3064663.3064714

Fallman, D. (2003) Design-oriented human-computer interaction, Proceedings of the SIGCHI conference on Human factors in computing systems, pp. 225-232, ACM Press.

Fish, J. and Scrivener, S. (1990) Amplifying the mind's eye: Sketching and visual cognition. Leonardo Vol 23 No 1, pp. 117-126.

Gaver, W. (2012) What should we expect from research through design? Proceedings of the SIGCHI Conference on Human Factors in Computing Systems, ACM, Austin, Texas, USA, 937-946.

Gaver, W. (2011) Making Spaces: How Design Workbooks Work. In Proceedings of the ACM Conference on Human Factors in Computing Systems (CHI 2011). ACM, 1551-1560

Gaver W. and Bowers, J. (2012) Annotated portfolios. interactions, 19 (4). 40-49.

Gedenryd, H. (1998) How Designers Work. Sweden: Lund University. Retrieved from. http://archive.org/details/HowDesignersWork-MakingSenseOfAuthenticCognitiveActivity. 
Gennawey, S. (2011) Walt Disney and the Promise of Progress City. Theme Park Press. pp. xiii. ISBN 1941500269

Golembewski, M. and Selby, M. (2010) Ideation decks: a card-based design ideation tool. In Proceedings of the 8th ACM Conference on Designing Interactive Systems (DIS '10). ACM, New York, NY, USA, 89-92. DOI=http://dx.doi.org/10.1145/1858171.1858189

Harrison, J. (2001) Thinking about tourists. International Sociology, 16, 159-172.

Jacucci, G., Oulasvirta, A., Ilmonen, T., Evans, J., Salovaara, A., (2007a). CoMedia: Mobile group media for active spectatorship. In Proceedings of the SIGCHI conference on Human Factors in computing systems (CHI'07). (pp. 1273-1282). New York, NY, USA: ACM.

Jacucci, G., Oulasvirta, A., and Salovaara, A. (2007b). Active construction of experience through mobile media: a field study with implications for recording and sharing. Personal Ubiquitous Comput, 11(4), 215-234.

Jones, K. R., and Wills, J. (2005). The invention of the park: From the Garden of Eden to Disney's magic kingdom. Oxford: Polity Press.

Kirby, D. (2009) The future is now: Diegetic prototypes and the role of popular films in generating realworld technological development, Social Studies of Science, 40, 41-70.

Martin, B and Hanington, B (2012) Universal Methods of Design. Rockport.

McCarthy, J., \& Wright, P. (2015) Taking [A]part: The Politics and Aesthetics of Participation in Experience-Centered Design, MIT Press.

McCarthy, J. and Wright, P. (2004) Technology as Experience. MIT Press.

McCloud, S. (2001) Understanding Comics. William Morrow Paperbacks.

Middleton, D. and Brown, S. D. (2005) The Social Psychology of Experience: Studies in Remembering and Forgetting. Sage.

Moggridge, B. (2007) Designing interactions, MIT Press.

Moore, A. (1980). Walt Disney World: Bounded ritual space and the playful pilgrimage center. Anthropological Quarterly, 53(4), 207-218.

Morrison, A., Tronstad, R. and E S Martinussen (2013) Design notes on a lonely drone, Digital Creativity, 24:1, 46-59, DOI: 10.1080/14626268.2013.768534

Nielsen, L. (2002, June). From user to character: an investigation into user-descriptions in scenarios. In Proceedings of the 4th conference on Designing interactive systems: processes, practices, methods, and techniques (pp. 99-104). ACM.

Nikolajeva, M., \& Scott, C. (2000) How Picturebooks work, Garland Press.

Nissen, B., Bowers, J., Wright, P. Hook, J. and Newell, C. 2014. Volvelles, domes and wristbands: embedding digital fabrication within a visitor's trajectory of engagement. In Proceedings of the 2014 conference on Designing interactive systems (DIS '14). ACM, New York, NY, USA, 825-834. DOI: http://dx.doi.org/10.1145/2598510.2598524

Petherbridge, D. (2010) The Primacy of Drawing: Histories and Theories of Practice, Yale University Press.

Pullman, P. (1998). Northern Lights: His Dark Materials 1 (Vol. 1). Scholastic Point.

Rennick-Egglestone, S., Brundell, P. Koleva, B., Benford, S., Roussou, M, and C. Chaffardon. 2016. Families and Mobile Devices in Museums: Designing for Integrated Experiences. J. Comput. Cult. Herit. 9, 2, Article 11 (May 2016), 13 pages. DOI: http://dx.doi.org/10.1145/2891416

Rowland, D., Porter, D., Gibson, M., Walker, K., Underwood, J., Luckin, R., Smith, H., Fitzpatrick, G., Good, J., Walker, B., Chamberlain, A., Rennick Egglestone, S., Marshall, J., Schnädelbach, H. and Benford, S. (2010) Sequential art for science and CHI. In CHI'10 Extended Abstracts on Human Factors in Computing Systems (CHI EA '10). ACM, New York, NY, USA, 2651-2660. DOI: http://dx.doi.org/10.1145/1753846.1753848

Salovaara, A., Jacucci, G., Oulasvirta, A., Kanerva, P., Kurvinen, E., Tiitta, S., (2006). Collective creation and sense-making of mobile media. In Proceedings of the SIGCHI conference on Human Factors in computing systems (CHI'06). (pp. 1211-1220). New York, NY, USA: ACM

Sarvas R, Frohlich DM. (2011) From Snapshots to Social Media - The Changing Picture of Domestic Photography. First Edition. Springer.

Schon, Donald A., and Glenn Wiggins. "Kinds of seeing and their functions in designing." Design studies 13.2 (1992): 135-156.

Scrivener S. A. R. and Clark, S. M. (1984) Sketching in collaborative design In. MacDonald L and Vince J (Eds.) Interacting with Virtual Environments Wiley, Chichester, U.K.

Sousanis, N. 2015. Unflattening. Harvard University Press, Cambridge, MA.

Tohidi, M., Buxton, W., Baecker, R. and Sellen. A. (2006) Getting the right design and the design right. In Proceedings of the SIGCHI Conference on Human Factors in Computing Systems (CHI '06), ACM, New York, NY, USA, 1243-1252. DOI: http://dx.doi.org/10.1145/1124772.1124960

Tovey, Michael. "Drawing and CAD in industrial design." Design Studies 10.1 (1989): 24-39.

Winograd, T. (1996) Bringing design to software. Reading, MA: Addison-Wesley.

Wright, P. \& McCarthy, J. (2005) The value of the novel in designing for experience, in Pirhonen, A.,

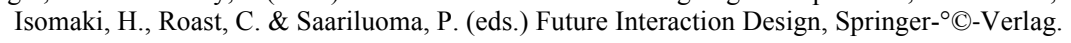



